\title{
Regeneration of cello-oligomers via selective depolymerization of cellulose fibers derived from printed paper wastes
}

\author{
Lee Ken Voon, Suh Cem Pang*, Suk Fun Chin \\ Faculty of Resource Science and Technology, Universiti Malaysia Sarawak, 94300 Kota Samarahan, Sarawak, Malaysia
}

\section{A R T I C L E I N F O}

\section{Article history:}

Received 15 October 2015

Received in revised form 8 January 2016

Accepted 14 January 2016

Available online 15 January 2016

\section{Keywords:}

Paper cellulose

Depolymerization

Ionic liquid

Acid catalyst

Cello-oligomers

\begin{abstract}
A B S T R A C T
Cellulose extracted from printed paper wastes were selectively depolymerized under controlled conditions into cello-oligomers of controllable chain lengths via dissolution in an ionic liquid, 1-allyl3-methylimidazolium chloride (AMIMCl), and in the presence of an acid catalyst, Amberlyst 15DRY. The depolymerization process was optimized against reaction temperature, concentration of acid catalyst, and reaction time. Despite rapid initial depolymerization process, the rate of cellulose depolymerization slowed down gradually upon prolonged reaction time, with $75.0 \mathrm{wt} \%$ yield of regenerated cello-oligomers (mean Viscosimetric Degree of Polymerization value of 81 ) obtained after $40 \mathrm{~min}$. The depolymerization of cellulose fibers at $80^{\circ} \mathrm{C}$ appeared to proceed via a second-order kinetic reaction with respect to the catalyst concentration of $0.23 \mathrm{mmol} \mathrm{H}_{3} \mathrm{O}^{+}$. As such, the cellulose depolymerization process could afford some degree of control on the degree of polymerization or chain lengths of cello-oligomers formed.
\end{abstract}

(c) 2016 Elsevier Ltd. All rights reserved.

\section{Introduction}

Lignocellulosic biomass resources such as agricultural residues, forestry wastes, waste paper, and energy crops have long been recognized as potential sustainable feedstocks for the production of biofuels and other biomaterials (Himmel et al., 2007). Paper wastes are mostly originated from wood pulp or cotton which consists of 90-99\% cellulose fibers (Sahin \& Arslan, 2008). Cellulose is a linear biopolymer which consists of anhydroglucose units $\left(\mathrm{C}_{6} \mathrm{H}_{10} \mathrm{O}_{5}\right.$, AGU) bonded by $1,4-\beta$-glycosidic linkages. Cellulose can be defined as a syndiotactic polymer of glucose with anhydroglucose units which are rotated by $180^{\circ}$ against each other within the polymeric chain (Brodeur et al., 2011). Cellulose has been used as a renewable and biodegradable resource for the production of biofuels (Mascal et al., 2008; Li, Zhang, \& Zhao, 2009), and others functional chemicals such as cellulose acetate (Cetin, Buduneli, Atlihan, \& Kırılmaz, 2004; Meireles, Rodrigues Filho, Assunção, Zeni, \& Mello, 2007; Rodrigues Filho et al., 2008) and cellulose ether (McCormick \& Callais, 1987; Heinze \& Pfeiffer, 1999; Pushpamalar, Langford, Ahmad, \& Lim, 2006). The most crucial step in the conversion of paper cellulose into various value-added products involves hydrolysis or selective depolymerization of cellulose fibers into cellulosic

\footnotetext{
* Corresponding author. Tel.: +60 82583017; fax: +60 82583160.

E-mail addresses: suhcem@gmail.com, scpang@frst.unimas.my (S.C. Pang).
}

fragments, cello-oligomers or oligosaccharides. The depolymerization of cellulose can either occur in aqueous phase (Fan, Lee, \& Beardmore, 1980; Philippidis, Smith, \& Wyman, 1993), solution form (Sasaki, Fang, Fukushima, Adschiri, \& Arai, 2000; Li \& Zhao, 2007) or solid form (Meine, Rinaldi, \& Schüth, 2012) in the presence of acid or alkali as catalyst. Basically, acid and enzymatic hydrolysis of cellulose gives high yields of monomeric glucose, whereas the alkaline hydrolysis produces mainly short chain carboxylic acids at low yields (Verendel, Church, \& Andersson, 2011).

However, the depolymerization process was difficult to control due to the recalcitrance nature of cellulose attributed mainly to its extensive intra- and intermolecular hydrogen networks, the basicity of glycosidic bonds, and to a lesser extent, its high crystallinity (Rinaldi \& Schüth, 2009; Rinaldi, Meine, vom Stein, Palkovits, \& Schüth, 2010). Existing hydrolysis treatments require harsh conditions such as the use of acids at high temperature and pressures which lead to cello-oligomers degradation and generation of wastes (Mok, Antal, \& Varhegyi, 1992; Kim, Lee, \& Torget, 2001). Recent studies on the applications of ionic liquids have made great progress in providing a versatile platform for the utilization of cellulosic resources and the production of novel functional materials (Heinze, Schwikal, \& Barthel, 2005; Cao et al., 2008; Feng \& Chen, 2008). Due to their unique properties such as chemical and thermal stability, non-flammability and very low vapor pressure (Huddleston et al., 2001; Wang, Li, Cao, \& Tang, 2011), ionic liquids are promising alternatives to conventional volatile organic solvents 